\title{
LEVANTAMENTO DO DIFERENCIAL TÉRMICO ENTRE OS MUNICÍPIOS DA BACIA HIDROGRÁFICA DO RIO PARAIBUNA - MG/RJ, PELO SENSOR TERMAL DO SATÉLITE LANDSAT 5
}

\author{
Valéria Valente Borges ${ }^{1}$ \\ Deborah Cristina Gomes de Oliveira ${ }^{2}$ \\ Ricardo Tavares Zaidan ${ }^{3}$
}

RESUMO: O presente trabalho abrange um zoneamento da temperatura da Bacia do Rio Paraibuna - MG/RJ, a partir do sensoriamento remoto termal de imagens do satélite Landsat 5. A sua elaboração se baseou no levantamento do diferencial térmico dos municípios contidos na bacia, e averiguar a atuação dos principais objetos sensoriados nos registros termais. Os resultados demonstram diferenças de até $14{ }^{\circ} \mathrm{C}$ entre áreas urbanas e rurais, sendo possível caracterizar determinados usos antrópicos como potencializadores da variação de temperatura.

Palavras-chave: Temperatura. Sensoriamento Remoto. Bacia do rio Paraibuna.

\section{INTRODUÇÃO}

\footnotetext{
${ }^{1}$ Bolsista de Iniciação Científica - Curso de Geografia/DEGEO/ICH/UFJF - lelavalent@yahoo.com.br.

${ }^{2}$ Bolsista de Iniciação Científica - Curso de Geografia/DEGEO/ICH/UFJF - deborahgeo ufif@yahoo.com.br.

${ }^{3}$ Prof. Adjunto - DEGEO/ICH/UFJF - ricardo.zaidan@ufjf.edu.br.
} 
Destacando-se perante as demais geotecnologias em estudos ambientais, o sensoriamento remoto fornece dados com grande amplitude espacial e temporal, permitindo o conhecimento e o monitoramento de uma dada área ou fenômeno, além de possuir boa acessibilidade, que torna possível os estudos em diferentes escalas. (NASCIMENTO, 2009).

O sensoriamento remoto, por ser um conjunto de atividades cujo objetivo consiste na caracterização das propriedades físico-químicas de alvos naturais, através da detecção, registro e análise de fluxo de energia radiante, por eles refletido e/ou emitido, apresenta-se como uma valiosa ferramenta com várias aplicabilidades (ROSA, 2003), dentre elas, a capacidade de estimar a temperatura da superfície.

Com o crescimento urbano, que vem alterando as condições ambientais, e gerando um desconforto térmico, podem ocorrer fenômenos de ilhas de calor, identificados principalmente nas áreas mais urbanizadas, e que afetam a saúde e o bem-estar da população. Além de esse ser um fator que condiciona a qualidade de vida de uma população. Nesse sentido, a fisionomia das cidades aliada aos fatores dinâmicos (como as condições do tempo) irão impor aos habitantes das cidades, o resultado das interferências humanas na dinâmica dos sistemas ambientais (BORGES, 2009).

A partir da análise obtida pelo sensoriamento remoto termal, dos fenômenos e transformações ambientais que alteram a temperatura da superfície terrestre, é possível planejar as tomadas de decisões sobre o espaço, além de the propor melhores adequações, garantindo assim, aumento na qualidade de vida das pessoas, no que diz respeito ao conforto térmico, e também, às atividades relacionadas ao atendimento da defesa civil.

A temperatura da superfície assim, como foco deste estudo, é também, um elemento constituído na dinâmica dos estudos de bacias hidrográficas. A área em análise, Bacia Hidrográfica do Rio Paraibuna, foi escolhida por estabelecer um importante papel na evolução do terreno, sendo uma unidade apropriada para o entendimento da ação dos processos hidrológicos e geomorfológicos, assim como também, das ligações espaciais e antrópicas.

Netto, (1998) ressalta que uma bacia de drenagem, enquanto uma unidade geomorfológica, constitui um sistema aberto na medida em que recebe impulsos 
energéticos das forças climáticas atuantes sobre sua área e das forças tectônicas subjacentes, e perde energia por meio da água e sedimentos exportados pela bacia no seu ponto de saída. Mas há também, as influências dos elementos e dos processos característicos, os quais constituem a organização interna do sistema de bacia de drenagem.

Com uso de Sistema de Informação Georreferenciada (SIG), o sensoriamento remoto termal pode então, auxiliar em diferentes aproveitamentos no estudo do espaço geográfico, assim como no estudo da dinâmica da espacialização da temperatura.

O satélite Landsat 5 promove esse imageamento da superfície, com o sensor TM (Thematic Mapper) produzindo imagens com $185 \mathrm{~km}$ de largura no terreno, e com 7 bandas espectrais. Cada banda representa uma faixa do espectro eletromagnético captada pelo satélite, e possui a resolução espacial de $30 \mathrm{~m}$, exceto a banda 6 do infravermelho termal $(10,4-12,5 \mu \mathrm{m})$, que possui uma resolução de $120 \mathrm{~m}$.

É importante citar aqui também, a temperatura aparente registrada dentro destes pixels da banda 6, que terá um valor correspondente à média dos registros de cada objeto contido nesse pixel, e por isso, chamamos de temperatura aparente ou estimada.

O estudo do conforto térmico das cidades requer uma análise de toda a organização complexa do clima urbano, o qual admite uma visão sistêmica, com vários graus de hierarquia funcional e diferentes níveis de resolução. Uma análise geográfica coerente do sistema clima urbano (SCU) pode ser encaminhada pelo estudo de três canais de percepção, diferentes, mas intrinsecamente associados uns aos outros, conforme Monteiro (2003):

O canal 1 trata do Campo Termodinâmico, no qual são enfatizados os estudos de ilhas de calor e de frescor urbanas, do conforto/desconforto térmico, de inversões térmicas, etc;

O canal 2, do Campo Físico-químico ou Dispersão, voltado à análise da dinâmica do ar na sua interação com a cidade, destacando a poluição do ar, a relação entre a estrutura urbana e os ventos etc;

O Terceiro é o Campo Hidrometeórico, relacionado ao estudo das precipitações urbanas e seus impactos. 
As componentes termodinâmicas do clima (canal I - Termodinâmico) não só conduzem ao referencial básico para a ação do conforto térmico urbano, como são, antes de tudo, a constituição do nível fundamental de resolução climática para onde convergem e se associam todas as outras componentes (MONTEIRO, 2003).

Atualmente, as informações obtidas pelo sensoriamento remoto do ambiente são cruciais para diversas análises do espaço, principalmente através da aplicação do infravermelho, que vem subsidiando o mapeamento térmico das cidades, ponto de partida para outros fenômenos do clima urbano, além de conduzir à elaboração de documentos que mostram a distribuição espacial e a grandeza de alguns de seus elementos (MONTEIRO, 2003).

Convém salientar que vários são os métodos de investigação de áreas quentes. $A$ utilização de dados provenientes de estações meteorológicas oficiais (a exemplo, do Instituto Nacional de Meteorologia - INMET) e a coleta local de dados de temperatura do ar em mini-abrigos termométricos são os mais indicados, pela confiabilidade do valor real dos dados. Porém, sua espacialização não apresenta a adequação quanto à compreensão do fenômeno, visto que a representação dos valores de temperatura do ar em isolinhas não informa a real extensão dos valores, mas sim, a extensão da variação entre aqueles coletados, resultando deste modo, numa forte generalização (NASCIMENTO, 2009). Este fato justifica o emprego do sensoriamento remoto termal como técnica do presente estudo, que tem por finalidade, comparar as discrepâncias da temperatura estimada através de imagens do satélite Landsat 5, dos municípios contidos na Bacia Hidrográfica do Rio Paraibuna.

\section{2. ÁREA DE ESTUDO}

A Bacia Hidrográfica do Rio Paraibuna abrange 37 municípios e ocupa uma área de cerca de $8.592 \mathrm{~km}^{2}$, compreendendo os estados de Minas Gerais e Rio de Janeiro (figura 1). 

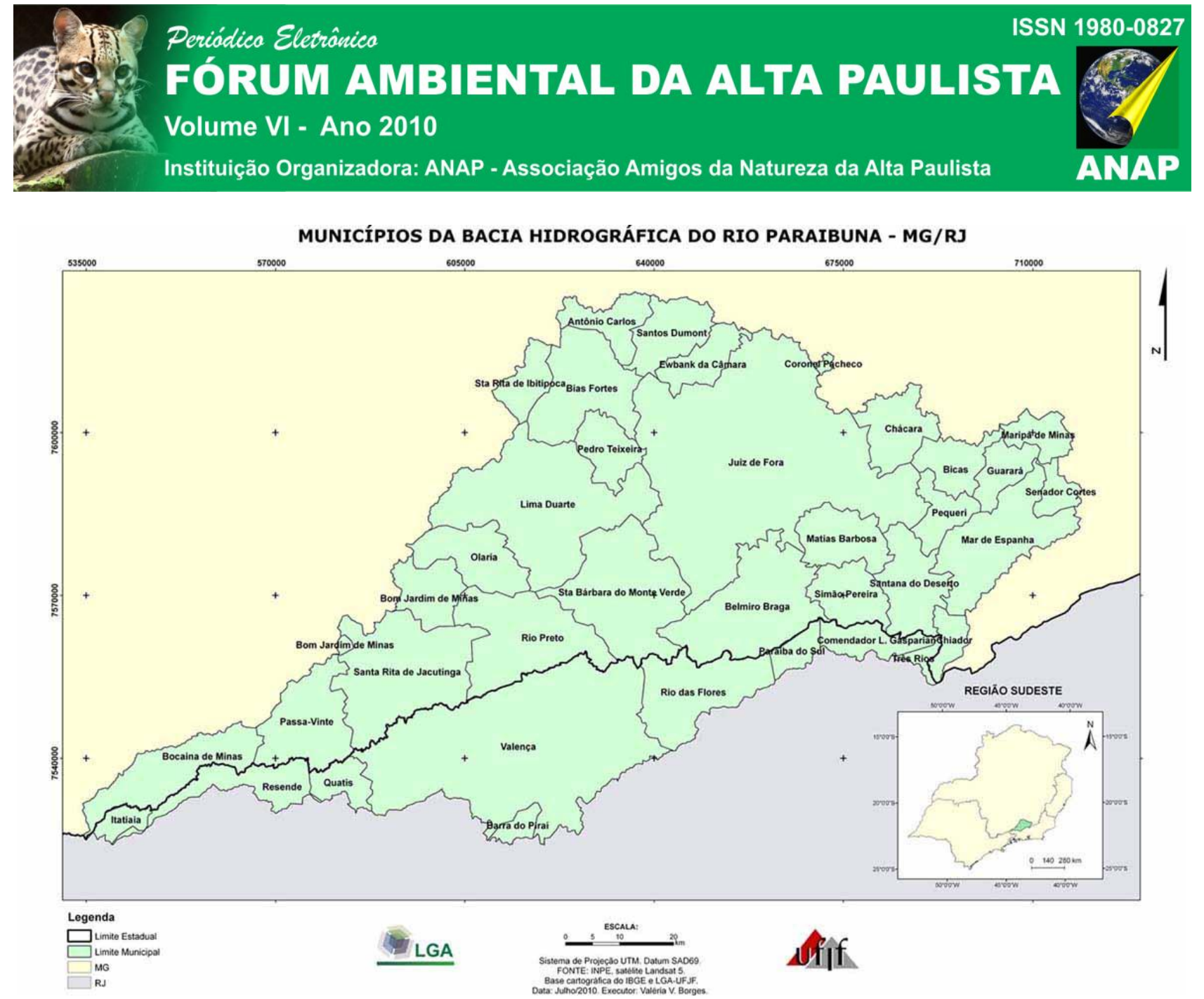

Figura 1 - Localização geográfica da Bacia Hidrográfica do Rio Paraibuna, no contexto da região Sudeste.

As altitudes mínimas e máximas variam entre $261 \mathrm{~m}$ e $2.764 \mathrm{~m}$, sendo os valores mais elevados de altitude referentes à Serra do Itatiaia (Pico das Agulhas Negras), junto à nascente do rio Preto, na zona sudoeste da bacia. Desta forma há uma amplitude altimétrica em torno de 2.503 m (ARAÚJO, 2009).

De acordo com o uso da terra, Silva, (2010) salienta que a principal atividade econômica rural da bacia é a pecuária leiteira, visto que as pastagens predominam na região, chegando a $72,41 \%$ de sua área total. E a cidade de Juiz de Fora se destaca nesse contexto, por ser, dentre as demais cidades localizadas na Bacia Hidrográfica do Rio Paraibuna, a de maior importância econômica e a que mais influenciou na produção do espaço nessa citada unidade espacial.

\subsection{DESENVOLVIMENTO}


Para obter os registros termais dos municípios localizados na Bacia Hidrográfica em estudo, foram utilizadas quatros cenas de órbita/pontos 217-75, 217-76 (do dia 05/09/2008), e 218-75, 218-76 (do dia 12/09/2008), do satélite Landsat 5, obtidas a partir do Instituto Nacional de Pesquisas Espaciais (INPE). Tal período foi escolhido, por corresponder um mês com menos chuvas, e assim, com menos quantidade de nuvens possível.

Conforme os Infoclimas do Boletim climatológico do Centro de Previsão de Tempo e Estudos Climáticos - CPTEC (http://infoclima1.cptec.inpe.br/), na época em análise deste trabalho (mudança da estação de Inverno para Outono), havia condições de neutralidade no Oceano Pacífico, ou seja, sem fenômenos de El Niño e La Niña, sendo assim, um período adequado ao estudo.

A partir do software IDRISI, pelo módulo termal, foi feita a transformação do número digital em valores de temperatura aparente da banda 6 de cada cena.

Com a mosaicagem das quatro cenas (figura 2), realizada no software ENVI, de licença temporária, foi feita a correção geométrica pelo interpolador de Alocação de Vizinho Mais Próximo (nearest neighbor), por ser o mais recomendado, devido à preservação dos valores de nível de cinza, já que todo pixel na imagem registrada recebe o valor de nível de cinza mais próximo na imagem original (NASCIMENTO, 2009). 


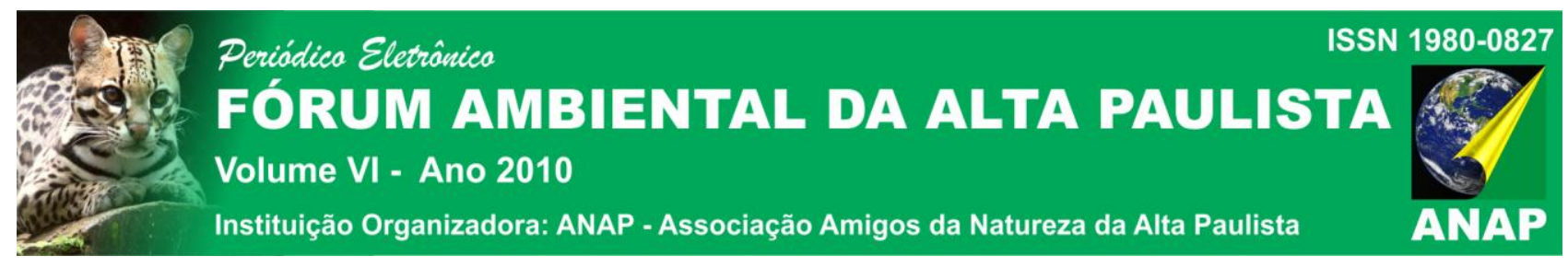

BACIA HIDROGRÁFICA DO RIO PARAIBUNA - MG/RJ: MOSAICO DE CENAS LANDSAT 5

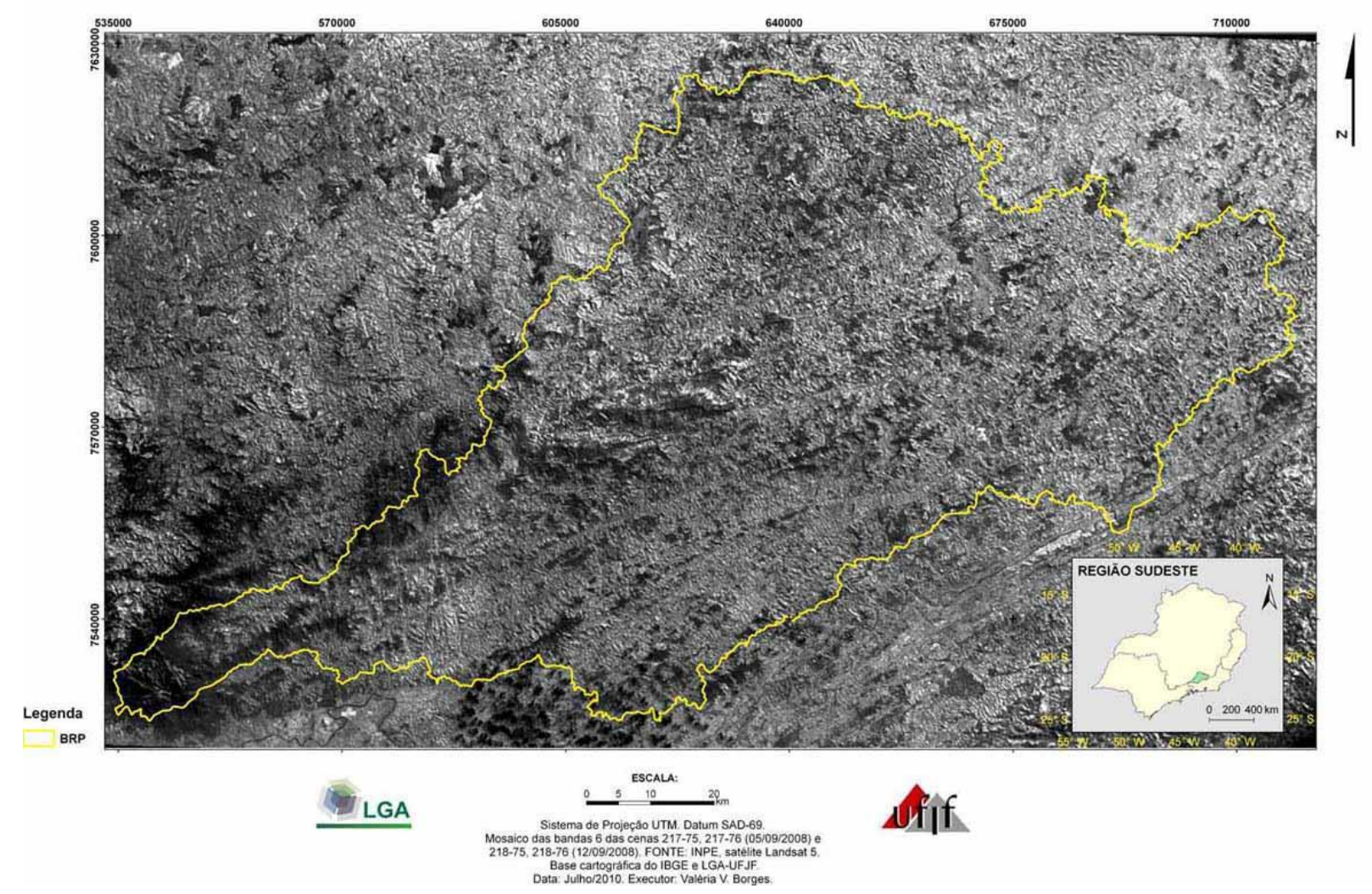

Figura 2 - Mosaico das cenas da banda termal do Landsat 5, da bacia hidrográfica em análise.

A classificação da temperatura $\left(\mathrm{em}^{\circ} \mathrm{C}\right)$ aparente, e as edições finais dos mapas foram realizadas a partir do software ARCGIS. Os registros mínimo e máximo foram, respectivamente, de $2{ }^{\circ} \mathrm{C}$ e $36^{\circ} \mathrm{C}$ (figura 3). 


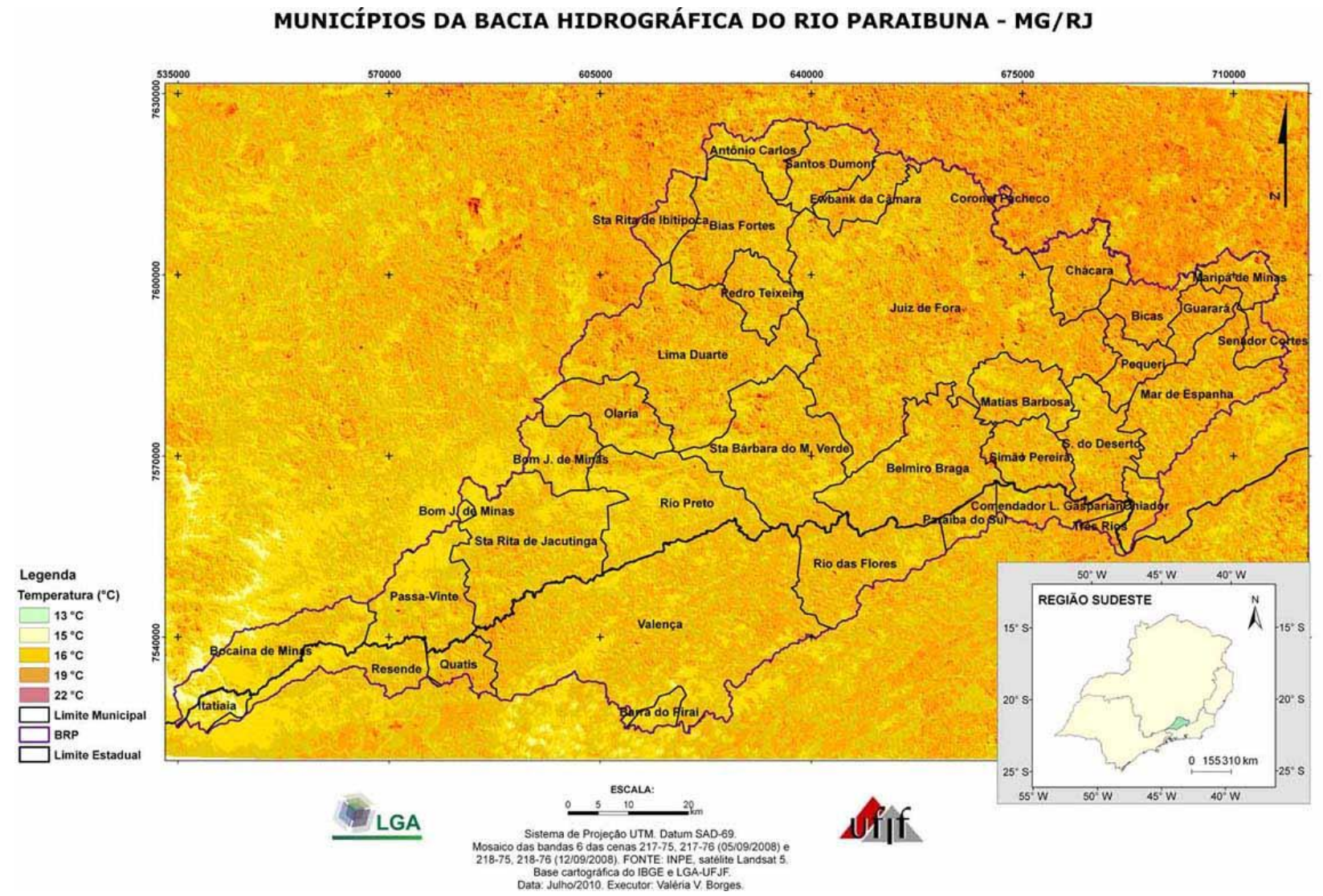

Figura 3 - Mapa termal da Bacia do Rio Paraibuna, obtido a partir da transformação dos números digitais em valores de temperatura aparente.

A partir da demarcação dos municípios obtida pelo IBGE, foram realizados os recortes de cada um sobre o mosaico com os valores das temperaturas, obtendo-se daí, uma maior quantidade de pixels para determinado valor. Sabendo-se da maior quantidade de pixels em cada município, pôde-se constatar, a moda da temperatura, ou seja, o valor da temperatura que mais ocorreu (tabela 1).

Importante citar aqui, as áreas de alguns municípios nos limites da bacia, que correspondem de fato, às áreas pertencentes à Bacia Hidrográfica do Rio Paraibuna, e não, à área total desses municípios. 
Tabela 1 - Temperatura Predominante dos Municípios da Bacia do Rio Paraibuna

\begin{tabular}{|c|c|c|}
\hline MUNICÍPIOS & Área & $\begin{array}{c}\text { Temperatura } \\
\text { Predominante }\left({ }^{\circ} \mathrm{C}\right)\end{array}$ \\
\hline Itatiaia & 43.472 .364 & 13 \\
\hline Resende & 146.680 .586 & 15 \\
\hline Bocaína de aminas & 239.319 .427 & 16 \\
\hline Barra do Piraí & 359.82 .257 & 16 \\
\hline Antonio Carlos & 110.366 .963 & 18 \\
\hline Belmiro Braga & 394.076 .870 & 18 \\
\hline Bias Fortes & 283.513 .112 & 18 \\
\hline Bom J. de Minas & 135.366 .405 & 18 \\
\hline Ewbank da Câmara & 103.803 .131 & 18 \\
\hline Lima Duarte & 618.384 .282 & 18 \\
\hline Matias Barbosa & 156.912 .948 & 18 \\
\hline Olaria & 178.398 .141 & 18 \\
\hline Pedro Teixeira & 112.247 .710 & 18 \\
\hline Rio Preto & 347.290 .450 & 18 \\
\hline Paraíba do Sul & 52.808 .203 & 18 \\
\hline Rio das Flores & 270.374 .090 & 18 \\
\hline Três Rios & 22.694 .419 & 18 \\
\hline Passa-Vinte & 245.389 .410 & 18 \\
\hline Santana do Deserto & 181.995 .482 & 18 \\
\hline Santos Dumont & 147.063.133 & 18 \\
\hline Simão Pereira & 134.805 .085 & 18 \\
\hline Sta Bárbara do M. Verde & 414.996 .702 & 18 \\
\hline Sta Rita de Jacuntinga & 436.368 .995 & 18 \\
\hline Valença & 1.126 .937 .519 & 18 \\
\hline Quatis & 73.327 .494 & 19 \\
\hline Juiz de Fora & 1.435 .355 .071 & 22 \\
\hline Bicas & 111.946 .039 & 22 \\
\hline Chacara & 151.429 .193 & 22 \\
\hline Chiador & 57.785 .948 & 22 \\
\hline Coronel Pacheco & 9.619 .933 & 22 \\
\hline Guarara & 88.588 .035 & 22 \\
\hline Mar de Espanha & 313.311 .990 & 22 \\
\hline Maripá de Minas & 77.251 .289 & 22 \\
\hline Pequeri & 90.678 .262 & 22 \\
\hline
\end{tabular}




\section{FÓRUM AMBIENTAL DA ALTA PAULISTA}

Volume VI - Ano 2010

Instituição Organizadora: ANAP - Associação Amigos da Natureza da Alta Paulista

\section{Comendador L. Gasparian \\ Senador Cortes}

Santa Rita de Ibitipoca
96.564 .585
53.050 .829
88.662 .555
22

22

22

De acordo com a temperatura aparente predominante em cada município, foi feito um mapa (figura 4) para melhor visualização e distinção das áreas mais quentes.

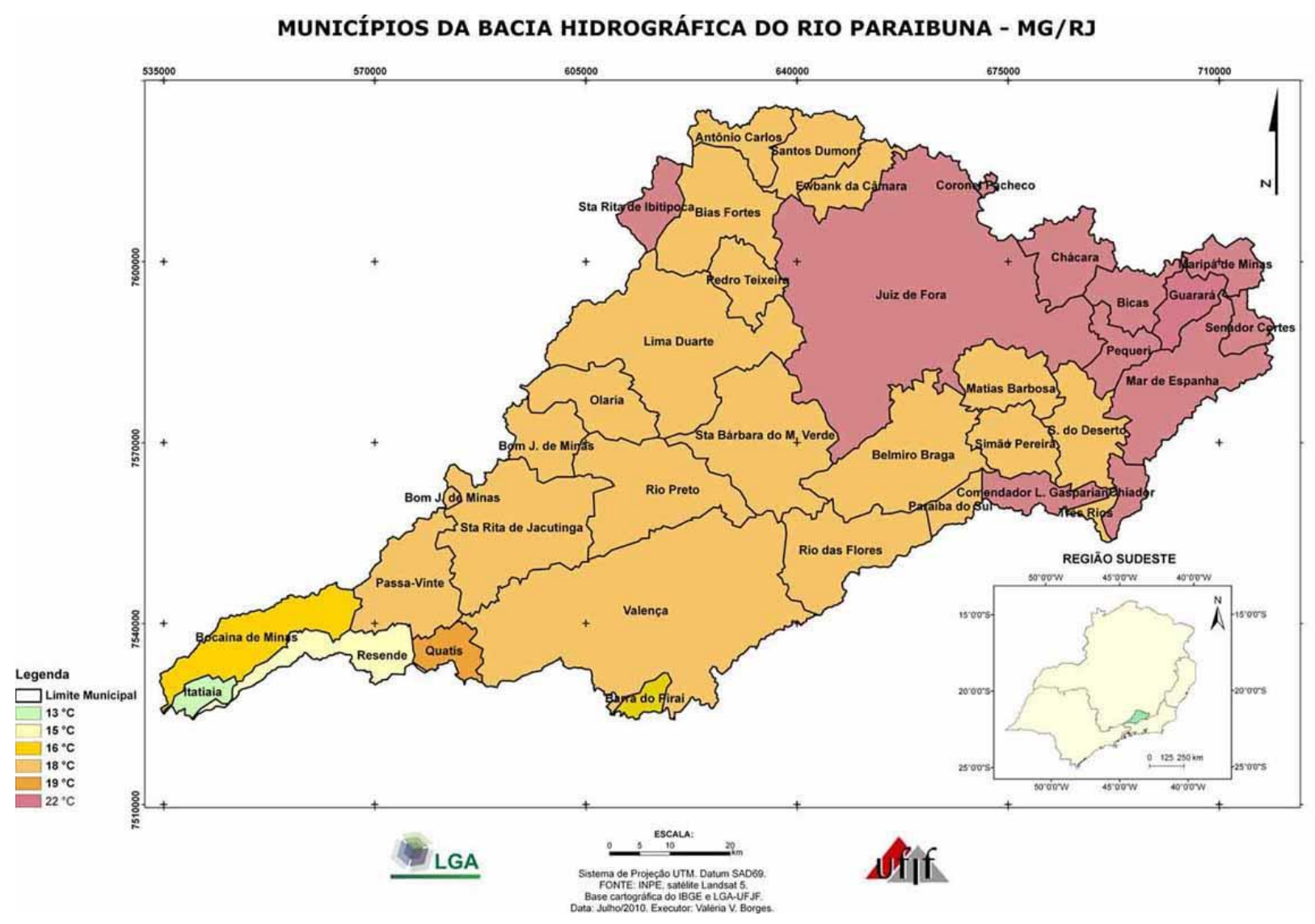

Figura 4 - Mapa discriminando a temperatura aparente dos municípios da bacia.

\subsection{CONCLUSÃO}

Pôde-se observar, que os menores registros de temperatura (entre $13^{\circ} \mathrm{C}$ e $16{ }^{\circ} \mathrm{C}$ ) foram detectados em regiões de mata (floresta estacional e vegetação secundária) e os maiores (de $18^{\circ} \mathrm{C}$ à $22^{\circ} \mathrm{C}$ ), situados em regiões de pastagens, locais de queimadas, e algumas edificações. 
As áreas mais ao norte da bacia, onde situam os municípios de Mar de Espanha, Chiador, Maripá de Minas, Juiz de Fora, Pequeri, entre outros, obtiveram os valores de temperatura mais elevados.

Os menores valores foram identificados nos municípios localizados na porção sudoeste, e sul, como Itatiaia, Resende, Barra do Piraí, que, de fato, localizam-se em regiões de maiores concentrações de matas, e mais elevadas. Ressalta-se aí, o forte papel da cobertura vegetal e dos corpos hídricos na amenização da temperatura.

Tal estudo mostrou-se satisfatório no âmbito do levantamento dos registros termais, e pode fornecer ainda, nesse sentido, subsídios para análises futuras dos condicionantes térmicos dos municípios da Bacia do Rio Paraibuna.

Dentre as técnicas de se quantificar as áreas quentes e ilhas de calor, o sensoriamento remoto termal se justifica pela melhor distribuição espacial dos dados, e a possibilidade de alcançar a espacialização da temperatura, para a partir daí, relacionar com outros elementos e fatores intrínsecos da análise térmica urbana.

\section{REFERÊNCIAS}

ARAÚJO, J. P. de C. Utilização de Métodos e Critérios para Determinação de Rio Principal em Bacias Hidrográficas: $O$ Caso do Rio Paraibuna. 1. Juiz de Fora: UFJF, 2009. 109p.

BORGES, V. V.; ZAIDAN, R. T.; MARTINS, L. A. Mapeamento, Zoneamento e Análise Termal por Sensoriamento Remoto do Município de Juiz de Fora, MG. In: SIMPÓSIO BRASILEIRO DE GEOGRAFIA FÍSICA APLICADA, 13., 2009, Viçosa. Anais... Viçosa: UFV, 2009. p. 1-8.

Centro de Previsão de Tempo e Estudos Climáticos - CPTEC. Boletins. São Paulo. 2008. Disponível em: http://infoclima1.cptec.inpe.br/. Acesso em: 18 de jul. 2010.

Instituto Nacional de Pesquisas Espaciais - INPE. Imagens do Satélite Landsat 5, cenas: 217-075 e 217-076 do dia 05/09/08; 218-075 e 218-076 do dia 12/09/08. Disponível em: http://www.dgi.inpe.br/CDSR/. Acesso em 12 de mai. 2010. 


\section{FÓRUM AMBIENTAL DA ALTA PAULISTA}

Volume VI - Ano 2010

MONTEIRO, C. A de F.; MENDONÇA, F. Clima Urbano. $1^{\text {a }}$. ed. São Paulo: Contexto, 2003. $192 \mathrm{p}$.

NASCIMENTO, D. T. F.; BARROS, J. R. Utilização da Banda Termal para Levantamento de Valores de Temperatura: Uma Discussão Inicial do Emprego de Dados Orbitais na Identificação de llhas de Calor. In: SIMPÓSIO BRASILEIRO DE GEOGRAFIA FÍSICA APLICADA, 13., 2009, Viçosa. Anais... Viçosa: UFV, 2009. p. 1-11.

NETTO, A. L. C.; GUERRA., A. J. T. \& CUNHA, S. B. da (Org.). Geomorfologia: Uma Atualização de Bases e Conceitos. $3^{\mathrm{a}}$. ed. Rio de Janeiro: Bertrand Brasil, 1998. 472 p.

ROSA, R. Introdução ao Sensoriamento Remoto. $5^{\text {a }}$ ed. Uberlândia: Universidade Federal de Uberlândia. 2003. 238 p.

SILVA, A. C. Zoneamento do Uso do Solo e Cobertura da Terra na Bacia do Rio Paraibuna por Imagens do Satélite Landsat 5. 1. Juiz de Fora: UFJF, 2010. 67p. 